\title{
Evidence for color vision in procyonides: Comparison between diurnal coatis (Nasua) and nocturnal kinkajous (Potos flavus)
}

\author{
MONIKA CHAUSSEIL \\ Institut für Zoologie, Tierärztliche Hochschule Hannover, Hannover, Germany
}

\begin{abstract}
The color-vision capacity of two species of procyonides was analyzed using a binary simultaneous discrimination paradigm. To make hue the only salient cue, the color sets of red, yellow, green, and blue were each presented in five different saturation intervals and were tested against a variety of brightness steps. Unlike the nocturnal kinkajous, the diurnal coatis showed highly significant discriminative performance on the color problems, especially in tests on blue and yel. low, yet failed to differentiate unsaturated green from achromatic stimuli. The results are discussed with respect to procedural variables and the utility of color discrimination in the coati's natural environment.
\end{abstract}

With the exception of primates (Blakeslee \& Jacobs, 1985; Jacobs \& Blakeslee, 1984; Mervis, 1974; Reeves, 1983; Swartz \& Rosenblum, 1980; Tigges, 1963), most mammals, according to Rodieck (1973), appear to be completely colorblind. Among the few diurnal forms studied, color vision has been demonstrated, for example, in squirrels (Anderson \& Jacobs, 1972; Jacobs, 1978), whose retinae are supposed to be heavily conedominated, tree shrews (Shriver \& Noback, 1967; Snyder, Killackey, \& Diamond, 1969), and pinnipeds (Busch \& Dücker, 1987).

The reports on color vision in procyonides are sparse and have exclusively concerned the North American raccoon (Procyon lotor). In an early study (Cole \& Long, 1909), these animals succeeded in selecting a piece of colored paper from a series of five colors and some gray stimuli. But the authors' conclusion-that the subjects possessed color vision-is questionable, since no effort was made to eliminate brightness as a possible cue. Gregg, Jamison, Wilkie, and Radinsky (1929), who studied color vision in dogs, cats, and raccoons, obtained only negative results. The raccoon's sensitivity for brightness differences, however, was found to be excellent (Cole \& Long, 1909; Munn, 1930). Tests with another nocturnal member of the Procyonidae, the kinkajou, also indicated a highly developed capacity for brightness discrimination (Chausseil \& Löhmer, 1986).

Since most procyonides are nocturnal, they are generally considered somewhat unpromising subjects for colorvision research. The coati, however, is diurnal and might be expected to possess at least some color vision. Despite its diumal habits, the coati's eye contains a reflective tape-

Requests for reprints should be addressed to Monika Chausseil, Institut für Zoologie, Tierärztliche Hochschule Hannover, Bunteweg 17. 3000 Hannover 1, Germany. tum, like that of other procyonides, thus showing structural adaptations more typically associated with nocturnality (Walls, 1963). This appears to reinforce the likelihood that the coati's diurnal activities were acquired secondarily, evolving from a nocturnal ancestor.

Unlike kinkajous, whose nocturnal activity heavily depends on arboreal feeding in tropical forests (PoglayenNeuwall, 1962), coatis are an extremely versatile group ecologically, occupying a wide range of environmental niches such as rocks, woodland, desert-scrub regions, and evergreen forests (Kaufmann, 1962; Kaufmann, Lanning, \& Poole, 1976). Yet virtually nothing is known about the physiology of the visual system of coatis and kinkajous. In any case, according to Mervis (1974), and Burtt (1979), the presence of chromatic mechanisms, as shown by neurophysiological or neuroanatomical evidence, does not necessarily indicate a subject's actual use of color vision; the latter has to be verified by a behavioral test of some sort. Therefore, the present study attempts to behaviorally determine whether coatis, with their diurnal habits and versatile activities, may possess the potential for color perception. Furthermore, given the considerably different lifestyles of coatis and kinkajous, the present study investigates a possible difference in the visual capacities of the two species.

\section{METHOD}

\section{Subjects}

Four coatis ( 2 males, 2 females) and 4 kinkajous ( 2 males, 2 females) were used as subjects. The coatis were about 6 years old; the kinkajous ranged from 10 to 17 years of age. They were housed in large cages $(2.35 \times 2.9 \times 4 \mathrm{~m})$ with branches, bars, and trunks to permit climbing and jumping. Their daily diet consisted of seasonal fruit and vegetables, together with chicken meat. Multivitamin juice was added once a week. All the subjects were experienced in a variety of learning tasks such as form discrimination, brightness discrimination, and concept formation, but none had any prior experience in color discrimination. Unfortunately, 1 of the coatis 
(Male A) died shortly after the first tests were executed, so the main part of the coatis' experiments was accomplished with only 3 subjects.

\section{Apparatus and Stimuli}

The tasks were conducted in the context of a binary simultaneous discrimination paradigm. The test apparatus (Figure 1) has been described in detail in an earlier study (Chausseil, 1991). Briefly, two different stimulus cards could be fitted into frames that were fixed in front of small feeding boxes with food access (small pieces of banana) as reward. Having been constructed above the ground, the test apparatus met the animals' natural climbing ability.

Usually, the paradigm employed to test color vision is to use filters varying the spectral composition of the stimuli. In such cases, the ambient illumination needs to be very dim. In the present study, colored paper was preferred to filters with regard to the advantage of working with fully light-adapted animals (with special respect to the diurnal coatis). The stimuli were pieces of colored cardboard, $18 \times 24 \mathrm{~cm}$. The colors used were red ("cadmium red deep"), yellow ("yellow ochre"), green ("viridian matt"), and blue ("cobalt blue"), all by PRIMAcryl, Schmincke, Germany.

The critical control for all studies of color perception is based on the elimination of brightness as a possible cue. Therefore, a set of 21 gray shades was introduced to be tested against the color stimuli. The set consisted of a series of photographic papers (Ilford Ilfospeed $1.24 \mathrm{M} ; 18 \times 24 \mathrm{~cm}$ ) that had been differently exposed to light (from unexposed white to black), and pasted on stiff cardboard. To preclude the possibility that the subjects may have responded to the color stimulus on the basis of an intensity cue, each color was offered in five different saturation intervals. This was accomplished by unsaturating the initial color by linearly increasing amounts of white ("titan white," PRIMAcryl, Schmincke). The luminance readings of both the hue and the achromatic discriminanda are shown in Table 1 . The numbers of the gray shades also represent the photographic exposure time (in seconds), and will be referred to as $\mathrm{Gl}, \mathrm{G} 2$, and so forth. The five hue numbers, respectively, indicate decreasing chromatic content with the color becoming increasingly unsaturated, and will be referred to as Red 1, 2, 3, 4, 5; Yellow 1, 2, 3, 4, 5, and so forth. The size of the five lu-

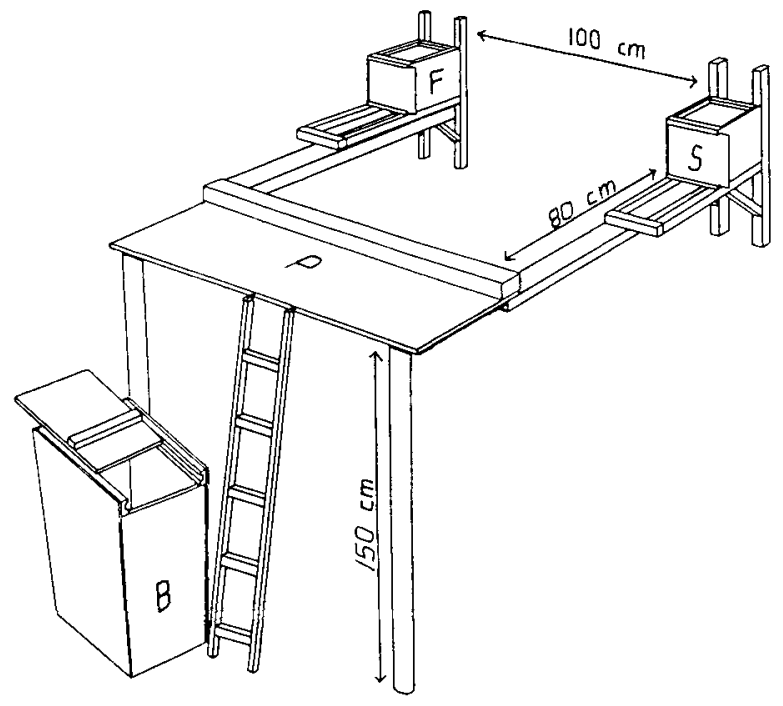

Figure 1. Apparatus used for training and tests. $B=$ box to lock subjects, $F=$ feeding box, $P=$ platform from where to choose, $S=$ stimulus card.
Table 1

Luminance Reading (in cd/m $\mathbf{m}^{2}$ ) of Brightness Intervals (Gray Shades) and Hues, Measured at the Level of the Center of the Stimulus Card

\begin{tabular}{ccccc}
\hline $\begin{array}{c}\text { Brightness } \\
\text { Intervals } \\
\text { (Gray Shades) }\end{array}$ & $\begin{array}{c}\text { Luminance } \\
\text { Reading } \\
\left(\mathrm{cd} / \mathrm{m}^{2}\right)\end{array}$ & Hue & $\begin{array}{c}\text { Luminance } \\
\text { Reading } \\
\left(\mathrm{cd} / \mathrm{m}^{2}\right)\end{array}$ \\
\hline 1 (white) & 12.79 & Red & $1^{*}$ & 6.82 \\
2 & 11.79 & & 2 & 7.0 \\
3 & 11.3 & & 3 & 7.23 \\
4 & 9.8 & 4 & 7.45 \\
5 & 8.9 & & 5 & 8.3 \\
6 & 8.3 & Yellow 1 & 8.18 \\
7 & 7.77 & & $2^{*}$ & 8.3 \\
8 & 7.36 & & 3 & 8.54 \\
9 & 7.23 & & 4 & 8.76 \\
10 & 6.96 & & 5 & 9.17 \\
11 & 6.82 & Green & $1^{*}$ & 7.23 \\
12 & 6.78 & & 2 & 7.77 \\
13 & 6.68 & & 3 & 8.0 \\
14 & 6.66 & & 4 & 8.3 \\
15 & 6.62 & & 5 & 9.04 \\
16 & 6.59 & Blue & 1 & 6.41 \\
17 & 6.57 & & 2 & 6.96 \\
18 & 6.55 & & $3^{*}$ & 7.23 \\
19 & 6.44 & 4 & 7.77 \\
20 & 6.41 & & 5 & 8.54 \\
21 (black) & 6.32 & & & \\
\hline
\end{tabular}

*Training hue (exception: Red 3 for kinkajous).

minance steps was still great enough to arouse color sensations (as they appeared to the human eye), which were clearly analyzable blends of the initial color quality, and yet were distinctly separate saturation blocks. The highest chromatic content (l) was brilliantly saturated, and the lowest (5) appeared to be a mere "tint" of the initial hue. Thus, it could be supposed that any discrimination based on an absolute hue sensation was reduced to near chance levels.

Luminance measurements were made with a Mavolux electronic luxmeter (Gossen, Erlangen, Germany). Two light sources (Südlicht-Endstrahler, Germany) mounted on the ceiling of the test room were used to continuously illuminate the stimulus cards. Ambient illumination was $150 \mathrm{~lx}$, and was readjusted every day. The background and adjoining walls were painted a homogeneous white.

To make brightness an irrelevant cue, each hue saturation was tested against various gray shades. According to Jacobs (1981), the achromatic stimulus should be varied over a sufficient range of luminances to assure that it will be brighter than, darker than, and equal in brightness to the tested hue. Since the spectral sensitivities of coatis and kinkajous are unknown, it is, however, hardly possible to specify points of equal brightness. In contrast, it is likely that the brightness match between a colored surface and a gray surface may differ for the coati and the kinkajou (at least for some wavelengths). This phenomenon is related to the Purkinje shift. For example, two grays that match red and green in luminance for the coati may be very different from two grays that match the same colors for the kinkajou. As mentioned, an electronic meter was used to measure the luminance of colored and gray papers. Generally, the spectral sensitivity curve of these meters approximates the curve for an average human subject under photopic conditions, so readings from a surface necessarily correspond to human luminance perception. In the present case, the human value was used as an approximation together with a sufficient range of luminances to control for the brightness problem. To prevent the coatis and kinkajous from solving the problem by making absolute brightness judgmentsavoiding the stimulus that was brighter than, or darker than the colored stimulus-the size of luminance steps employed was very 
small. On the average, a set of five different brightness intervals was selected (for detailed data, see Tables 2 and 3 ).

\section{Procedure}

The animals were tested daily, just prior to their normal feeding time. In training, the subjects were presented with a positively reinforced color of constant saturation versus nonreinforced black. The right and left position of the reinforced stimulus appeared equally often in a predetermined random sequence with the restriction that no position was positive for more than three consecutive trials. These restrictions helped the subjects avoid position habits. If an animal did develop position habits, the tests were discontinued and, instead, the negative stimulus appeared continuously on the preferred position until the animal redirected its attention toward the stimuli. The subjects were not allowed to correct themselves if their choice was wrong. After making a choice, the subjects were locked in a box to prevent them from watching the preparation for the next trial. The mean intertrial interval was $1 \mathrm{~min}$, the testing session for each subject lasted approximately $50 \mathrm{~min}$, and the intersession interval was $24 \mathrm{~h}$. During the sessions, the experimenter stood $1.5 \mathrm{~m}$ from the test apparatus and recorded the choices on each trial. Because the experimenter stood behind the subjects, it was not possible to give them inadvertent cues by expression or movement.

To avoid possible auditory cues while changing the position of the stimuli, a continuous position change was simulated before each trial by moving both stimulus cards, even if the position remained the same. In the course of the experiments, both feeding boxes acquired the scent of banana. In addition, both boxes were rubbed with banana prior to each testing session.

The learning criterion was met when the percentage of correct responses had reached at least $76 \%$ in a daily session of 25 trials for six consecutive days. Once performance stabilized under these conditions, tests were executed 2 days after the last training session. In the first experiment, the stimulus combination consisted of the training hue versus white. The brightness reversal of the negative stimulus was presented on the grounds that the subjects, if they possessed no color vision whatever, would be likely to choose the relatively brighter stimulus (as they did in training). In subsequent tests, each hue saturation was paired with different gray shades, and tested at least 25 times (see Tables 2 and 3). In the final test, each of the five saturation intervals of an appropriate color was presented against five different brightness steps. For example, for tests on red, the order of stimulus presentation was Red $1,2,3,4,5$ versus $\mathrm{G} 6$ in five consecutive trials, $\operatorname{Red} 1,2,3,4,5$ versus $G 8$ in the next five trials, and so forth, up to $\operatorname{Red} 1,2,3,4,5$ versus G11 in the last five trials (for details, see Results). Therefore, the subjects were not only exposed to a variety of gray shades, but to different hue saturations as well. These tasks were conducted within 25 sessions, each session consisting of at least 25 trials.

The significance levels were determined using a binomial expansion based upon the number of alternatives in the array (Ramm \& Hofmann, 1982). During the tests, all discriminanda were presented without reexposing the animals to any previously presented stimulus. To avoid retraining, both stimuli were baited during the tests. The coatis were the first to be tested.

\section{RESULTS}

\section{Coatis}

For each animal, the chronological order of the colors presented in training and tests was red, blue, yellow, green. All coatis learned to discriminate the positive colors from the nonreinforced black. During training, there was evidence of interproblem improvement as the trials to criterion decreased within the sequence of colors employed. The mean number of trials required was 287 on Red 1 versus black, 138 on Blue 3 versus black, 100 on Yellow 2 versus black, and 30 on Green 1 versus black.

Table 2 indicates the average performance on tests with red and yellow. In the first test, when presented with a

Table 2

Responses to Red (Left Panel) and Yellow (Right Panel) With Mean Performance of 3 Coatis* and Significance Levels

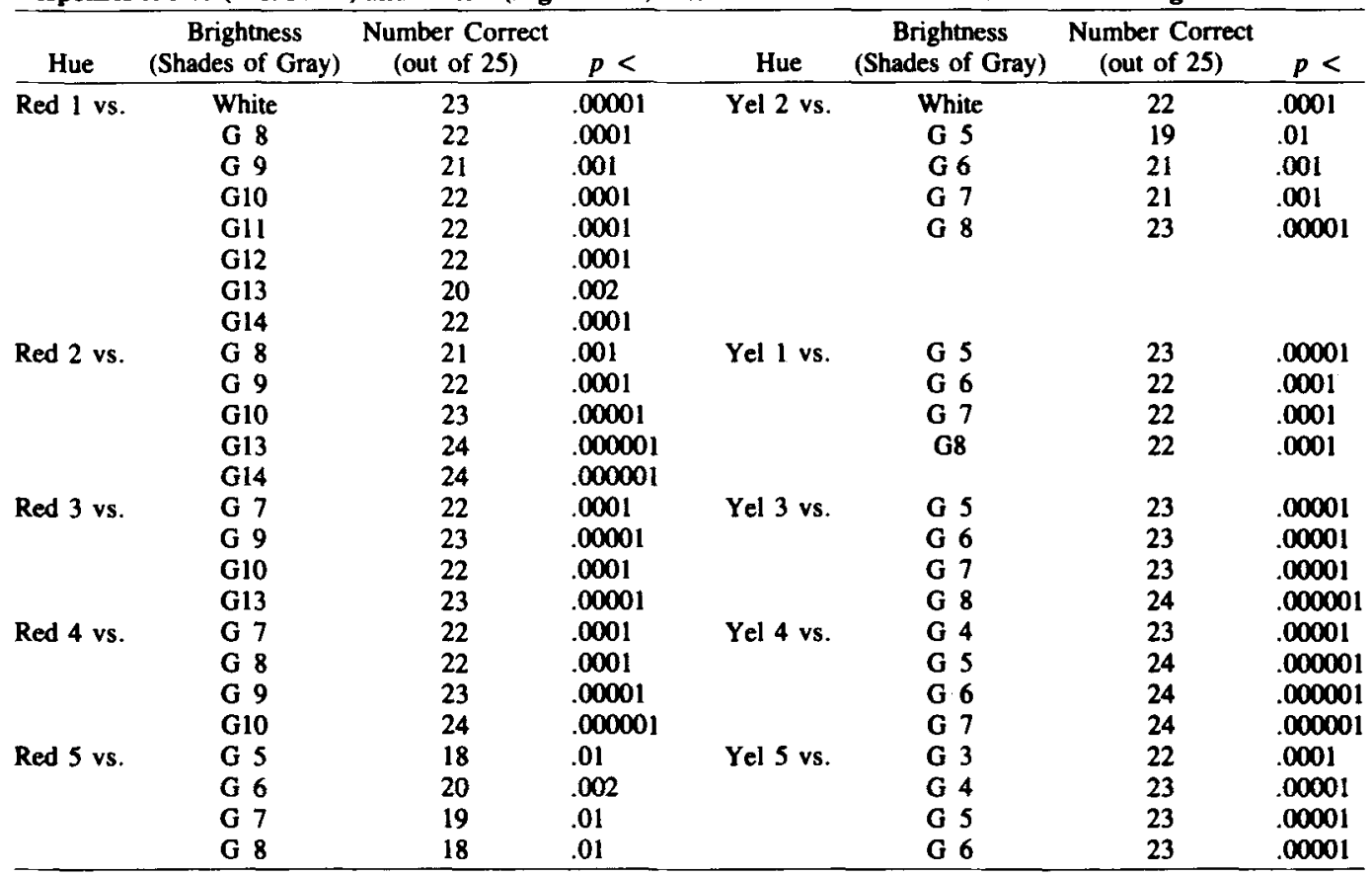

Note-Presented are both hues in five intensities. The respective hues were tested against different brightness intervals in shades proof gray (G). *Tests with Red 1 still include the fourth subject, Male 4. 
color versus white, the animals did not choose the relatively brighter stimulus, but significantly preferred the color. Furthermore, the data show that the subjects responded just as correctly when the color saturation was altered. Performance on Red 5 was less consistent but was still significantly better than chance $(p<.01)$. Male A developed an illness that necessitated discontinuing the experiment after tests on Red 1 had been conducted; he died soon afterward.

Table 3 presents the average performance on tests with green and blue. When exposed to blue, the animals were able to successfully distinguish between all hue saturations and the range of achromatic stimuli employed, and made almost no errors. Tests on green, however, revealed quite different results: Although the subjects were able to make discriminations over a wide range of stimulus pairs, the levels of correct responses were considerably lower than in tests with red, yellow, and blue. All subjects failed to achieve discriminative performance on lower hue saturations such as Green 5 .

The final test with five saturation intervals of an appropriate color, each presented against different brightness steps, is plotted in Figure 2, which shows the average performance of 3 coatis. The discriminanda employed were Red 1-5 versus G6, 8, 9, 10, and 11; Yellow 1-5 versus G4, 5, 6, 7, and 8; Green $1-5$ versus G5, 6, 7, 8 , and 9 ; and Blue $1-5$ versus G5, 6, 7, 9, 10, and 18 , respectively. Thus, the subjects were to discriminate between at least 25 stimulus combinations (30 in the case of blue) within the same test session. If they had no color perception, the animals would have been likely to con- fuse such a variety of different stimuli. The level of correct responses, however, was highly significant for tests on red $(p<.001)$, yellow $(p<.00001)$, and blue $(p<.000001)$. In contrast, the subjects showed great difficulty or failure in the final test on green. The average performance was still significantly better than chance $(p<.01)$, but the subjects made a substantially greater number of errors; Female B's scores were not above chance $(p<.10)$. Tests on green were extended to 50 sessions. In the final tests, the order of best color discrimination was blue $>$ yellow $>$ red $>$ green, thus clearly reflecting the performance of the previous tests when the hue saturations were still presented separately against the gray shades. No interproblem improvement could be seen during the tests.

\section{Kinkajous}

The chronological order of the colors presented to each subject was blue, red, yellow, green-different from that for the coatis. At the beginning of the training sessions, the 2 male kinkajous refused to respond to the red stimulus, so blue was taken for the first training set. When trained on Blue 3 versus black, all subjects were performing at chance levels $(50 \%)$ after 300 trials had been accomplished. On the assumption that a greater intensity difference between the positive and the negatlve stimulus may facilitate the learning process, a very bright gray (G3) was employed as a substitute for the hue (which was of subjectively medium brightness). Thereafter, the subjects achieved significant scores after an average of 175 trials. When reexposed to Blue 3, all subjects attained criterion

Table 3

Responses to Green (Left Panel) and Blue (Right Panel) With Mean Performance of 3 Coatis and Significance Levels

\begin{tabular}{|c|c|c|c|c|c|c|c|}
\hline Hue & $\begin{array}{c}\text { Brightness } \\
\text { (Shades of Gray) }\end{array}$ & Number Correct & $p<$ & Hue & $\begin{array}{c}\text { Brightness } \\
\text { (Shades of Gray) }\end{array}$ & Number Correct & $p<$ \\
\hline \multirow[t]{5}{*}{ Gre 1 vs. } & White & $20 / 25$ & .002 & Blue 3 vs. & White & $23 / 25$ & .00001 \\
\hline & G 8 & $18 / 25$ & .01 & & G 8 & $18 / 25$ & .01 \\
\hline & G 9 & $20 / 25$ & .002 & & G 9 & $24 / 25$ & .000001 \\
\hline & G10 & $21 / 25$ & .001 & & G11 & $24 / 25$ & .000001 \\
\hline & G12 & $20 / 25$ & .002 & & G13 & $24 / 25$ & .000001 \\
\hline \multirow[t]{5}{*}{ Gre 2 vs. } & G 5 & $21 / 25$ & .001 & Blue 4 vs. & G 6 & $25 / 25$ & .0000001 \\
\hline & G 6 & $22 / 25$ & .0001 & & G 7 & $25 / 25$ & .0000001 \\
\hline & G 7 & $21 / 25$ & .001 & & G 8 & $25 / 25$ & .0000001 \\
\hline & G 8 & $21 / 25$ & .001 & & & & \\
\hline & G 9 & $18 / 25$ & .01 & & & & \\
\hline \multirow[t]{5}{*}{ Gre 3 vs. } & G 5 & $21 / 25$ & .001 & Blue 5 vs. & G 4 & $24 / 25$ & .000001 \\
\hline & G 6 & $22 / 25$ & .0001 & & G 5 & $24 / 25$ & .000001 \\
\hline & G 7 & $18 / 25$ & .01 & & G 6 & $24 / 25$ & .000001 \\
\hline & G 8 & $16 / 25$ & .1 & & G 7 & $23 / 25$ & .00001 \\
\hline & G 9 & $17 / 25$ & .05 & & & & \\
\hline \multirow[t]{5}{*}{ Gre 4 vs. } & G 4 & $20 / 25$ & .002 & Blue 2 vs. & G 8 & $23 / 25$ & .00001 \\
\hline & G 5 & $19 / 25$ & .01 & & G 9 & $23 / 25$ & .00001 \\
\hline & G 6 & $34 / 50$ & .01 & & G10 & $23 / 25$ & .00001 \\
\hline & G 7 & $28 / 50$ & .1 & & G11 & $25 / 25$ & .0000001 \\
\hline & G 8 & $24 / 50$ & .5 & & G13 & $25 / 25$ & .0000001 \\
\hline \multirow[t]{5}{*}{ Gre 5 vs. } & G 3 & $21 / 25$ & .001 & Blue 1 vs. & G16 & $24 / 25$ & .000001 \\
\hline & G 4 & $26 / 50$ & .5 & & G18 & $24 / 25$ & .000001 \\
\hline & G 5 & $26 / 50$ & .5 & & G19 & $24 / 25$ & .000001 \\
\hline & G 6 & $25 / 50$ & .5 & & G20 & $24 / 25$ & .000001 \\
\hline & G 7 & $24 / 50$ & .5 & & & & \\
\hline
\end{tabular}

Note-Gre = green; $\mathbf{G}=$ gray . 


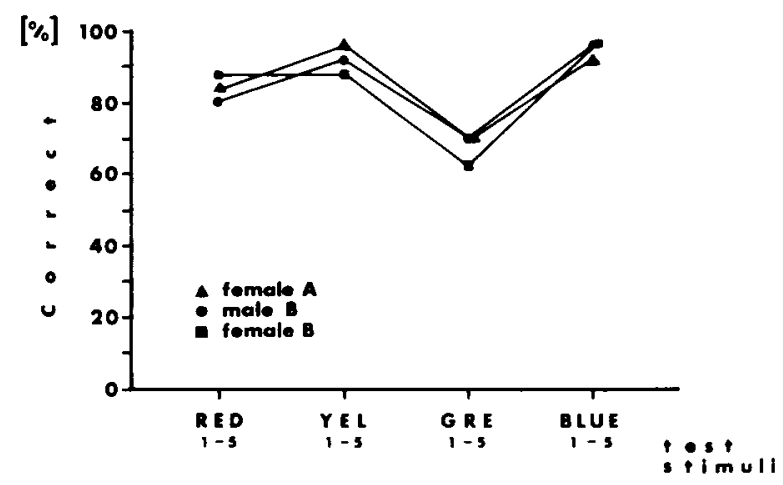

Figure 2. Final test with 3 coatis. Five saturation intervals of an appropriate color were each presented against a set of different brightnesses (for detailed data, see text). YEL = yellow, GRE = green.

within the first session. In the following training on red, the males no longer refused to respond to the stimuli.

Initially, Red 1 had been designated for the positive stimulus. Instead, it was decided post hoc that another hue saturation, Red 3, should be employed because of its greater intensity. G3 also served as a substitute for Red 3. Significant scores were achieved after an average of 75 trials. When finally presented with Red 3 versus black, all subjects attained criterion within the first session. In training on Yellow 2 versus black, and Green 1 versus black, no substitutes were used, and the criterion was met in the first training session. As the trials to criterion decreased within the order of training problems, there was evidence of interproblem improvement during the learning procedure.

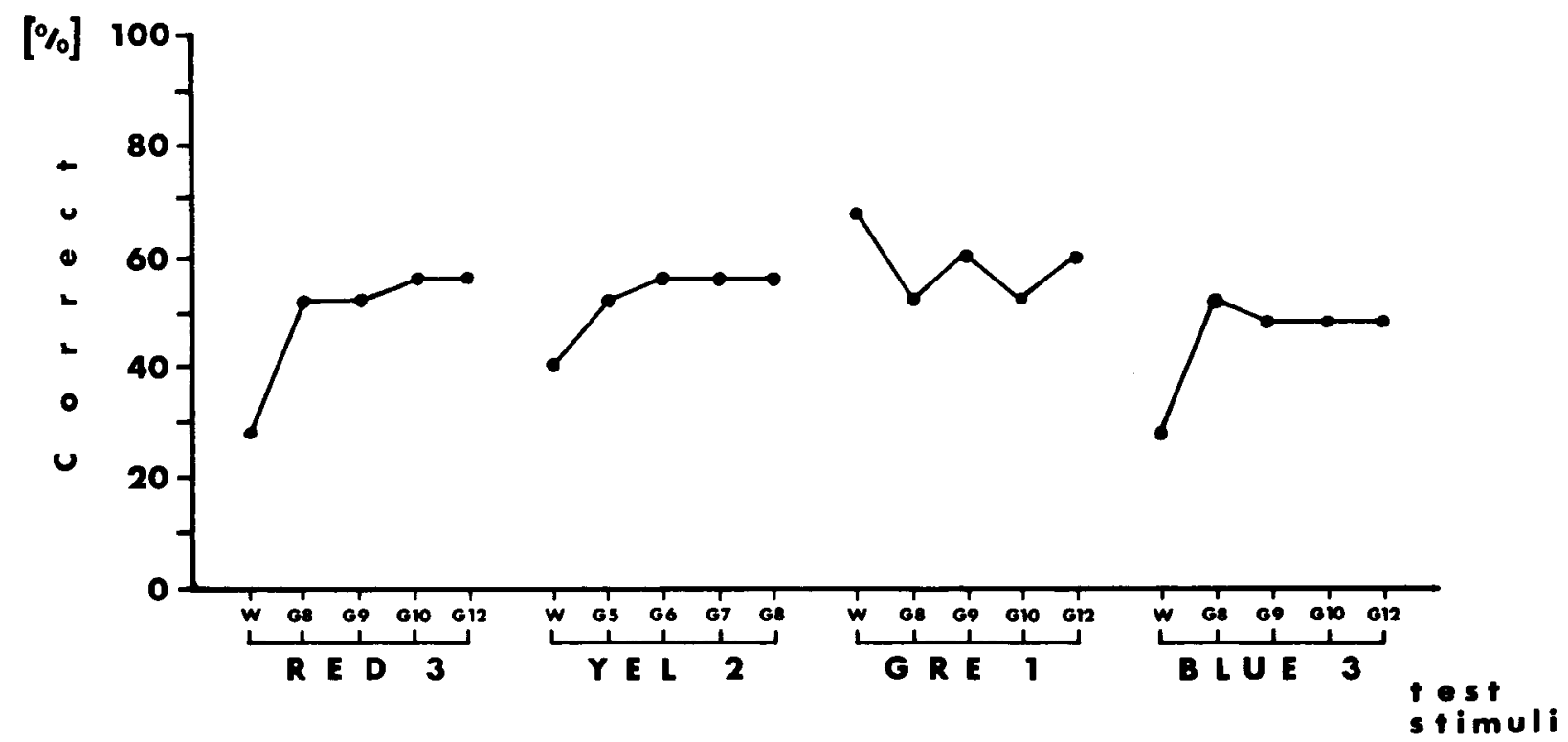

Figure 3 illustrates the average performance on Red 3, Yellow 2, Green 1, and Blue 3, each tested against various gray shades. When Blue 3 and Red 3, respectively, were presented against white, the subjects achieved scores of $28 \%$ correct $(7 / 25)$ in both cases, thus choosing the nonreinforced white $(p<.01)$. Performance on Yellow 2 versus white revealed scores of $40 \%$ correct $(10 / 25)$. The mean level of correct responses to Green 1 versus white was above chance $(68 \%)$, but was not significant $(p<.10)$, with Female A being the only subject to achieve a significantly better than chance score [80\% correct $(p<.002)]$.

When tested on color against a set of various gray shades, all subjects performed at chance levels. When chance performance was evident in all kinkajous at the end of 4,100 trials, the tests were terminated. Despite the low test scores, no differential reward was given so that the subjects would not learn each stimulus set anew. Former studies have shown that kinkajous are capable of learning new problems within a single test session (Chausseil, 1991). Additionally, their highly developed brightness acuity would have been likely to facilitate this learning ability during the tests. The strong interproblem improvement during the training sessions appears to emphasize this consideration.

\section{DISCUSSION}

The present study indicates that the coatis' successful performance was achieved on the basis of perceived color differences. In contrast, the results show no evidence for color perception in the kinkajous. The problems, apparatus, and experimental design were nearly identical for the

Figure 3. Average performance of 4 kinkajous on tests with Red 3, Yellow 2, Green 1, and Blue 3 versus brightnesses, as plotted on the abscissa. $\mathrm{YEL}=$ yellow, $\mathbf{G R E}=$ green, $\mathbf{W}=$ white. 
two species. Thus, the difference in performance seems to be attributable to different visual capacities, rather than to procedural variables.

It would, however, be of additional value to attempt to provide an explanation for this extreme difference in performance, with special respect to the visual capacities of both species, as established in former studies. As mentioned previously, the prior testing history of kinkajous involved experiments on brightness discrimination (Chausseil \& Löhmer, 1986), which indicated that the animals can discriminate between extraordinarily small differences in brightness. Therefore, it appears to be possible that, in the present study, brightness cues may have been utilized, contributing to the kinkajous' performance. Nevertheless, according to Jacobs (1981), motivated subjects will solve color-discrimination problems any way they can. Negative results must therefore be interpreted cautiously, since animals with exceptionally acute brightness vision might respond solely on the basis of brightness, yet may possess a modest color vision. This would have tended to compromise the kinkajous' performance, but, as they responded at chance levels in both of the tests, it reinforces the likelihood that brightness, not color, was in fact the salient cue. Moreover, the evidence for different visual capacities in the two species appears to be supported by previous tests with coatis, which have shown that the animals, when tested on a series of 20 gray shades, revealed a distinctly less sensitive brightness acuity than kinkajous (Chausseil, 1989). Unlike the nocturnal kinkajou, the brightness sensitivity of the coatis, like that of many other diurnal animals, correlated with the law of Weber-Fechner (Blackwell, 1972; Davson, 1980), in that it increased toward the darker end of the gray scale. These findings further suggest that, due to their nocturnal and diurnal habits, respectively, the two species might, in fact, possess different visual mechanisms.

Considering the coatis' successful performance on color versus gray shades, the question may arise as to whether saturation, intensity, or brightness of the stimuli could have provided cues that were involved in any of their color tests. Saturation is usually regarded as a more complex visual parameter than brightness, the psychological counterpart of physical intensity, or hue, and is therefore considered to be a less likely cue for color discrimination (McCleary \& Bernstein, 1959; Walls, 1963). Nevertheless, saturation was a controlled factor in this study since all colors were presented in various saturations, thus ruling out the possibility that the subjects responded on the basis of an absolute color cue. Moreover, the high number of hue saturations employed here may be the chief factor in control for brightness. Previous studies on animal color vision have used relatively few (if any) saturation intervals of the very same hue. Given the coatis' poor brightness acuity (compared to the kinkajous'), if they lacked color perception, then the subjects undoubtedly would have performed at chance levels when faced with such a variety of hue/brightness combinations. The final tests, presenting at the same time the whole saturation range of an appropriate hue against a set of various brightnesses, were determined to further confuse the subjects in case they did not possess color vision. However, the animals showed a highly significant performance, which could not have been achieved on the basis of brightness cues.

Although the sample of coatis employed here was small, it is noteworthy that there was no evidence for any individual differences in their performance. The three functions shown in Figure 2 are almost identical in shape, thus indicating that all subjects shared similar hue sensations.

A more general question concerns the usefulness of this capacity to the coatis in their natural environment. Because coatis are reported to be highly opportunistic omnivores (Kaufmann, 1962; Kaufmann, Lanning, \& Poole, 1976) it is probable that color vision aids in food selection. In the coati's diet, fruit may be considered the most colored food item. Most thoroughly studied is the coati's ecology in the tropical forests of Barro Colorado Island, Panama (Kaufmann, 1962), and in the colder woodlands and desert-scrub regions of the United States (Kaufmann, Lanning, \& Poole, 1976). The dry season in Panama is. the principal fruit season, and most arboreal feeding occurs then. Apart from greenish and brownish fruit (figs, almendros), coatis heavily feed on brightly colored fruits, such as black palms (Astrocaryum) and hogplums (Spondias), which are orange and yellow, respectively. In the southwestern United States and Mexico, they also eat juniper berries, which are bluish-black, as well as manzanita berries and madrone berries, which are red and dark red, respectively (Kaufmann, 1991). There are also reports of coatis feeding on cultivated crops such as peaches and bananas, which are both yellow colored. The performance on red, yellow, and blue in the present tests would be expected, given the colors described above.

According to Burtt (1979), the critical factor in color discrimination is likely to be the color of the background against which the colored fruits contrast. In the tropical rain forests, most of the coati's color discrimination may be between fruit colors aloft in tree tops, contrasting with blue sky or green foliage. In drier regions like desert scrub, grassland, or rocks, the vegetation and most soils reflect light most strongly in the long-wavelength part of the spectrum (Burtt, 1979; Nickerson, Kelly, \& Stultz, 1945). Therefore, yellow, orange, and desaturated red objects blend with the background and are thus more difficult to detect. Consequently, the coati's ability to successfully discriminate red and yellow enables them to locate, for example, yellow food items surrounded by yellow or brown vegetation. According to Burtt (1979), the light in shaded forest areas is always more saturated, is "greener" than the ambient light near the top of the forest, and is lower in total irradiance. This generality holds true for all kinds of forests and may be a possible explanation for the coatis' failure to differentiate the brighter intensities of green.

It is clear that the coatis' performance in the present tests does not reveal whether the mechanism of their color 
discrimination is dichromatic, trichromatic, or tetrachromatic. Hence, this study does not supplant traditional psychophysical procedures used to investigate the dimensionality of color perception. However, the results of this experiment give a reasonably clear picture of the basic color-vision capacities in a species whose diurnal activity is unique among the otherwise exclusively nocturnal procyonides. To determine how this capacity is produced will require supplementary approaches to the physiology of the visual system.

\section{REFERENCES}

Anderson, D. H., \& Jacobs, G. H. (1972). Color vision and visual sensitivity in the California ground squirrel (Citellus beecheyi). $V i$ sion Research, 12, 1995-2004.

BlaCkwell, H. R. (1972). Luminance difference thresholds. In D. Jameson \& L. M. Hurvich (Eds.), Visual psychophysics: Handbook of sensory physiology (pp. 78-100). New York: Springer-Verlag.

Blakeslee, B., Jacoss, G. H. (1985). Color vision in the ring-tailed lemur (Lemur catta). Brain Behavior \& Evolution, 26, 154-166.

BURTT, D. H. (1979). The behavioral significance of color. New York: Garland Press

BUSCH, H., \& DüCKER, G. (1987). Das visuelle Leistungsvermögen der Seebären (Arctocephalus pusillus und Arctocephalus australis). Zoologischer Anzeiger, 219, 197-224.

Chausseil, M. (1989). Visuelles Lernvermögen bei Nasenbären (Nasua Storr, 1780) und Wickelbären (Potos flavus Schreber, 1774). Doctoral dissertation, University of Hannover.

Chausseil, M. (1991). Visual same-different leaming, and transfer of the sameness concept by coatis (Nasua Storr, 1780). Ethology, 87, 28-36.

Chausseil, M., \& Löhmer, R. (1986). Untersuchungen über das Helligkeitssehen bei Wickelbären (Potos flavus Schreber, 1774). Zeitschrift für Säugetierkunde, 51, 274-281.

COLE, L. W., \& LONG, F. M. (1909). Visual discrimination in raccoons. Joumal of Comparative Neurological Psychology, 19, 657-683.

Davson, H. (1980). Physiology of the eye. New York: Academic Press. GregG, F. M., JAmison, E., Wilkie, R., RAdINSKY, T. (1929). Are dogs, cats, and raccoons colour-blind? Joumal of Comparative Psychology, 9, 379-395.

JACOBS, G. H. (1978). Spectral sensitivity and color vision in the grounddwelling sciurids: Results from golden mantled ground squirrels and comparisons for five species. Animal Behavior, 26, 409-421.
JACOBS, G. H. (1981). Comparative color vision. New York: Academic Press.

JACOBS. G. H., \& BLAKESLEE, B. (1984). Individual variations in color vision among squirrel monkeys (Saimiri sciureus) of different geographical origins. Journal of Comparative Psychology, 98, 347-357.

KAUfMANN, J. H. (1962). Ecology and social behavior of the coati (Nasua narica) on Barr Colorado Island, Panama (pp. 95-222). Los Angeles: University of California Press.

Kaufmann, J. H. (1991). Personal communication.

Kaufmann, J. H., Lanning, D. V., Poole, S. E. (1976). Current status and distribution of the coati in the United States. Journal of Mammalogy, 57, 621-637.

McCleary, R. A., Bernstein, J. I. (1959). A unique method for control of brightness cues in study of color vision in fish. Physiological Zoology, 32, 284-292.

MERVIS, R. F. (1974). Evidence of color vision in a diurnal prosimian, Lemur catta. Animal Learning \& Behavior, 1, 151-153.

MUNN, N. L. (1930). Pattern and brightness discrimination in raccoons Journal of Genetic Psychology, 37, 3-34.

Nickerson, D., Kelly, K. L., Stultz, K. F. (1945). Color of soils Journal of the Optical Society of America, 35, 297-300

Poglayen-Neuwall, I. (1962). Beiträge zu einem Ethogramm des Wickelbären (Potos flavus Schreber). Zeitschriff fur Saugetierkunde, 27, 1-64.

RAMm, B., \& HofmanN, G. (1982). Biomathematik und medizinische statistik. Stuttgart: Enke-Verlag.

ReEves, A. (1983). Sensitivity of the red-green channel in light and dark adaptation. In J. D. Mollon \& L. T. Sharpe (Eds.), Color vision, physiology and psychophysics (pp. 331-343) London: Academic Press.

RoDieck, R. W. (1973). The vertebrate retina: Principles of structure and function. San Francisco: W. H. Freeman.

Shriver, J. E., Noback, C. R. (1967). Color vision in the tree shrew (Tupaia glis). Folia Primatology, 6, 161-169.

Snyder, M., Killackey, H., Diamond, I. T. (1969). Color vision in the tree shrew after removal of the posterior neocortex. Journal of Neurophysiology, 32, 554-563.

SWARTZ, K. B., Rosenblum, L. A. (1980). Operant responding by bonnet macaques for color videotape recordings of social stimuli. Animal Learning \& Behavior, 8, 311-321.

Tigges, J. (1963). On color vision in gibbon and orangutan. Folia Primatology, 1, 188-198.

WALES, G. L. (1963). The vertebrate eye and its adaptive radiation New York: Hafner.

(Manuscript received July 2, 1991: revision accepted for publication March 23, 1992.) 